\title{
AN ANALYTICAL STUDY OF CLINICAL FEATURES IN 100 CASES OF PITYRIASIS ROSEA
}

\author{
Saravanan $N^{1}$, Sindhuja Ramasamy2, Murugan $S^{3}$, Sridhar $V^{4}$, Vanathi $T^{5}$, Sarathchandran $B^{6}$, G. P. Rekha \\ ${ }^{1}$ Associate Professor, Department of Dermatology, Venereology and Leprology, Chengalpattu Medical College. \\ ${ }^{2}$ Associate Professor, Department of Dermatology, Venereology and Leprology, Thanjavur Medical College. \\ ${ }^{3}$ Assistant Professor, Department of Dermatology, Venereology and Leprology, Chengalpattu Medical College. \\ 4 Senior Resident, Department of Dermatology, Venereology and Leprology, Chengalpattu Medical College. \\ 5Junior Resident, Department of Dermatology, Venereology and Leprology, Chengalpattu Medical College. \\ JJunior Resident, Department of Dermatology, Venereology and Leprology, Chengalpattu Medical College. \\ JJunior Resident, Department of Dermatology, Venereology and Leprology, Chengalpattu Medical College.
}

\section{ABSTRACT}

\section{BACKGROUND}

Objective- Pityriasis rosea is an acute self-limiting disease, probably infective in origin, affecting mainly children and young adults and characterised by distinctive skin eruption and minimal constitutional symptoms.

Aim of the study is to analyse the incidence of PR in Government General Hospital, Chengalpattu during the period from November 2016 to January 2017, age and sex distribution, probable aetiological factor, symptoms of PR, morphological types and distribution of PR, associated cutaneous findings and the course of the disease.

\section{MATERIALS AND METHODS}

100 self-reporting patients of age group 3 - 68 years with clinical features of Pityriasis rosea, who attended Dermatology OPD in Chengalpattu Medical College over a period of 6 months from September 2016 to February 2017 were enrolled.

\section{RESULTS}

Out of 100 cases studied 27 (27\%) were females and $73(73 \%)$ were males. Prodromal illness prior to the onset of rash was reported by 8 patients (8\%), of whom 1 had fever alone, 1 had fever with history of jaundice and 6 had upper respiratory tract infection. Itching was absent in 51 patients; 49 patients (49\%) had itching, of whom most patients (46) had only mild itch. Herald patch was present in 82 cases and absent in 18 cases. Both morphology and distribution were classical in $45 \%$ patients. In the remaining 55\%, atypical morphology and/or atypical distribution were observed. In our study, none of the patients had mucous membrane or nail involvement. In $81 \%$ of patients, the lesions resolved within a period of 6 - 8 weeks. Active acne vulgaris is seen in 5 patients, of whom 1 had eczema also and 1 had seborrhoeic dermatitis in addition. Post Acne scar is seen in 1 patient. Nevus achromicus is seen in 1 patient. Epidermal nevus in 1 patient and combined hypo- and hyperpigmented moles in 1 patient.

\section{CONCLUSION}

Clinical diagnosis of Pityriasis rosea was easy based on the presence of Herald Patch, characteristic morphology and distribution pattern of the lesions. The present study has revealed male preponderance. The age incidence was found to be high in adolescents and young adults. No familial incidence was observed. Factors like wearing of new garments, stress and upper respiratory tract infections were found to precipitate the disease in some cases. In most of the patients the lesions vanished without trace and postinflammatory hypopigmentation was noted in few patients, but none had hyperpigmentation. History of recurrence of the disease was also present in one case. Histopathological study showed the features of nonspecific chronic dermatitis.

\section{KEYWORDS}

Pityriasis rosea, Herald Patch, Patch, Types, Association.

HOW TO CITE THIS ARTICLE: Saravanan N, Ramasamy S, Murugan S, et al. An analytical study of clinical features in 100 cases of pityriasis rosea. J. Evolution Med. Dent. Sci. 2017;6(26):2142-2148, DOI: 10.14260/Jemds/2017/465

\section{BACKGROUND}

Pityriasis rosea is an acute self-limiting disease, probably infective in origin, affecting mainly children and young adults, and characterised by distinctive skin eruption and minimal constitutional symptoms.

Financial or Other, Competing Interest: None.

Submission 22-02-2017, Peer Review 18-03-2017,

Acceptance 24-03-2017, Published 30-03-2017.

Corresponding Author:

Sindhuja Ramasamy,

Associate Professor,

Department of Dermatology, Venereology and Leprosy,

Thanjavur Medical College,

Thanjavur Medical College Road,

Thanjavur-613004.

E-mail:dhunsi75@gmail.com

DOI: $10.14260 /$ jemds $/ 2017 / 465$
The initial lesion, Herald patch, is followed several days to weeks later by the appearance of numerous similarappearing smaller lesions, located along the lines of cleavage of the trunk (Christmas tree pattern). Pityriasis rosea has been reported in all races; the average annual incidence at one centre was reported to be 0.16 percent. It is more common between 10 and 35 years of age with equal sex distribution or a slight female preponderance HHV-6 and 7 may play a role extensively in some patients with PR. The various morphological types are macular, papular, vesicular, lichenoid, pustular, purpuric, urticarial and Erythema Multiforme (EMF) like. The lesions can occur anywhere on the skin but it is rarely seen over the scalp, palms and soles. After a period of about six to eight weeks, the lesions resolve spontaneously leaving a residual hypo- or hyperpigmentation without any complications. 


\section{MATERIALS AND METHODS}

The study was conducted at the Department of Dermatology, Chengalpattu Medical College during the period from September 2016 to January 2017. All the patients attending the Dermatology Outpatient Department were screened and patients with pityriasis rosea were enrolled. The clinical diagnosis of Pityriasis rosea (PR) was made in each case based on the morphology and distribution of the skin lesions. During the first visit of the patients their name, age, sex, address, occupation, income, etc. were noted. Complaints, probable precipitating factors, prodromal illness, contact and family history were also noted. A thorough examination of both general and systemic was carried out. Complete dermatological examination including the number, site, size, morphology and distribution of primary and secondary lesions followed by examination of palms and soles, hair, nail and mucous membrane was carried out. Based on this, patients were classified as classic or atypical variety of PR. Investigations like haemogram, urine and motion examination, skin scraping for fungus, blood VDRL, etc. were done. All the patients were given symptomatic treatment and followed up for a period of 3 months at weekly intervals. The sequelae and complications if any were recorded. Data thus obtained was complied, tabulated and statistically summarised.

\section{RESULTS}

In our study, maximum incidence was noted in the age group between 11 - 30 years (53\%). The youngest patient in the study was 3 years old and the oldest was 68 years old, which is similar to that reported in literature. Both sexes are equally susceptible according to some authors, while others quoted a female preponderance. ${ }^{1}$ In our study, a male predominance was observed. ${ }^{1}$

\begin{tabular}{|c|c|}
\hline Number of Males & Number of Females \\
\hline $73 \quad 27$ \\
\hline \multicolumn{2}{|c|}{ Table 1. Sex Incidence } \\
\hline
\end{tabular}

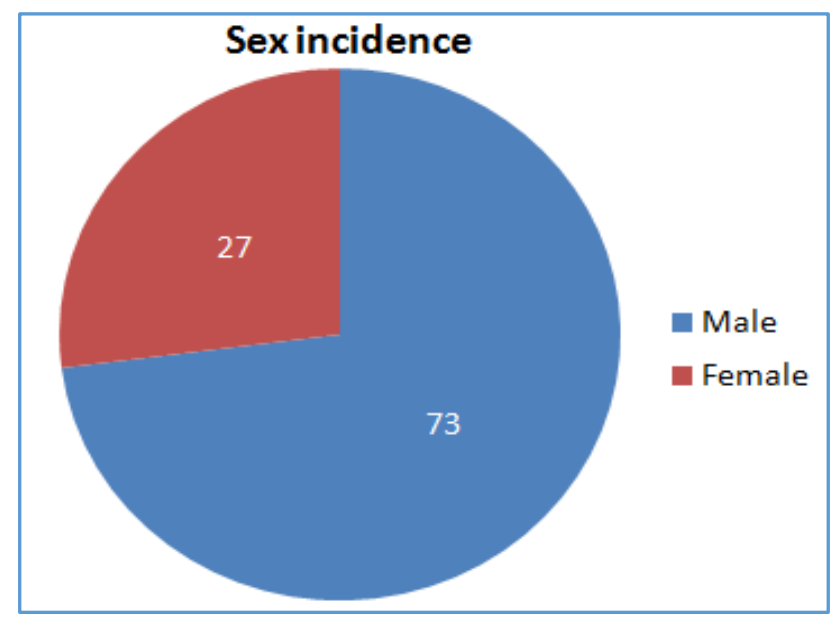

\begin{tabular}{|c|c|}
\hline Age in Yrs. & Number of Cases \\
\hline $0-10$ & 20 \\
\hline $11-20$ & 27 \\
\hline $21-30$ & 26 \\
\hline $31-40$ & 18 \\
\hline $41-50$ & 07 \\
\hline $51-60$ & 01 \\
\hline $61-70$ & 01 \\
\hline \multicolumn{2}{|c|}{ Table 2. Age distribution } \\
\hline
\end{tabular}

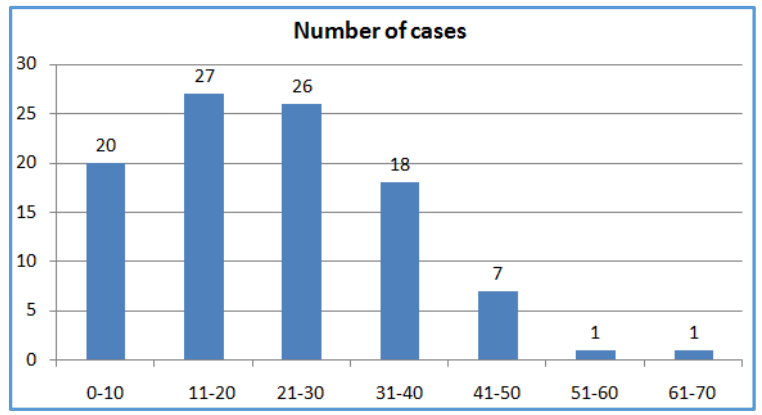

\section{Age/Sex Distribution}

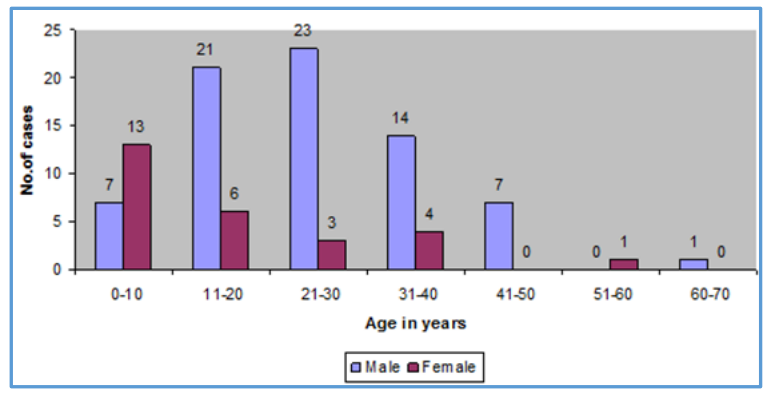

Literature states that wearing of new garments may precipitate or aggravate the disease. In our study, only 4 patients gave a history of wearing new garments prior to the onset of the disease. Other provoking factors like and psychogenic stress $(2 \%)$ were also recorded in the present study. Literature reports also indicate similar findings. ${ }^{2}$

Prodromal illness like upper respiratory tract infection and malaise were seen in 8 patients (8\%), similar to that seen in literature. Literature reports herald patch to be seen in $50 \%-90 \%$ of all PR patients, ${ }^{2}$ but in our study, it was noted in $82 \%$ of patients. The location of the herald patch has been seen to occur more frequently on the trunk (42\%) followed by upper limb and the thigh, which is similar to that reported in literature. The herald patch which probably represented the primary inoculation site of the virus according to various authors was seen to occur over the covered areas of the body. ${ }^{3}$ In our study also the herald patch was seen to occur over the covered areas of the body in majority (66\%) of the patients.

The Herald patch is absent or undetected in about $20 \%$ of cases. In our study also Herald patch was absent in $18 \%$ patients. Rarely, the Herald patch may be double or multiple, often close together. In our study also one patient had double Herald patch close together.

\begin{tabular}{|c|c|}
\hline Site of Herald Patch & No. of Patients \\
\hline Chest & 09 \\
\hline Abdomen & 07 \\
\hline Umbilicus & 02 \\
\hline Loin & 08 \\
\hline Back & 16 \\
\hline Shoulder & 02 \\
\hline Scapula & 01 \\
\hline Neck & 04 \\
\hline Face & 07 \\
\hline Upper limb & 13 \\
\hline Thigh & 09 \\
\hline Lower limb & 04 \\
\hline (Knee and below knee) & Table 3. Distribution of Herald patch \\
\hline \multicolumn{2}{|c|}{} \\
\hline \multicolumn{2}{|c|}{} \\
\hline
\end{tabular}


According to literature secondary lesions starts appearing after an interval of 5 - 15 days (few hours to 2 months), in crops at 2 - 3 days interval over 1 week to several weeks. In our study after a varying period ranging from 1 - 30 days following the appearance of the Herald patch, the generalised eruptions followed. They appeared in crops, intermittently at various intervals of 3 - 10 days.

The generalised eruptions have been found to manifest in various morphological forms like papular, vesicular, lichenoid, EMF-like purpuric, urticarial and pustular forms. ${ }^{4}$ In our study only papular, lichenoid, EMF-like lesions have been observed.

Distribution of the secondary eruption over scalp, face and penis has been reported to be uncommon. ${ }^{5}$ In our study no scalp involvement was seen, but 1 patient had penile lesions, 7 patients (7\%) had lesions over the face. Involvement of palm and soles is also uncommon and was seen in 3 patients (3\%).

Both morphology and distribution (typical bathing suit) were classical in 45\% patients. In the remaining 55\% atypical morphology and/or atypical distribution were observed.

\section{Atypical Morphology}

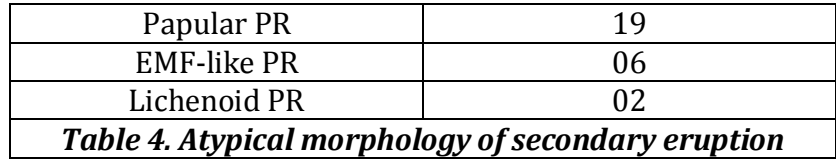

\section{Atypical Distribution}

\begin{tabular}{|c|c|}
\hline Inverse PR & 11 \\
\hline Unilateral PR & 01 \\
\hline Flexural & 03 \\
\hline \multicolumn{2}{|c|}{ Table 5. Atypical distribution of secondary eruption } \\
\hline
\end{tabular}

\section{Atypical Sites}

\begin{tabular}{|c|c|}
\hline Face & 07 \\
\hline Palm and soles & 03 \\
\hline Distal limb & 07 \\
\hline Penis & 01 \\
\hline Thigh & 02 \\
\hline Abdomen & 01 \\
\hline Table 6. Atypical sites of involvement \\
\hline
\end{tabular}

Literature states that Unilateral Pityriasis rosea has been reported. In our study, we had a case of Unilateral Pityriasis rosea.

Literature states that mucous membrane involvement is rare in PR, but may involve the oral and genital mucosa. In our study, mucous membrane involvement was not seen.

According to literature pruritus is mild in $25 \%$ of cases, $50 \%$ mild-to-moderate and $25 \%$ had severe itching. 1,6 In our study $46 \%$ of patients had mild itching, $1 \%$ moderate and $2 \%$ had severe itching, one of whom had history of swimming in river water.

\begin{tabular}{|c|c|}
\hline Grade & No. of Patients \\
\hline Absent & 51 \\
\hline Mild & 46 \\
\hline Moderate & 01 \\
\hline Severe & 02 \\
\hline \multicolumn{2}{|c|}{ Table 7. Grading of Itching } \\
\hline
\end{tabular}

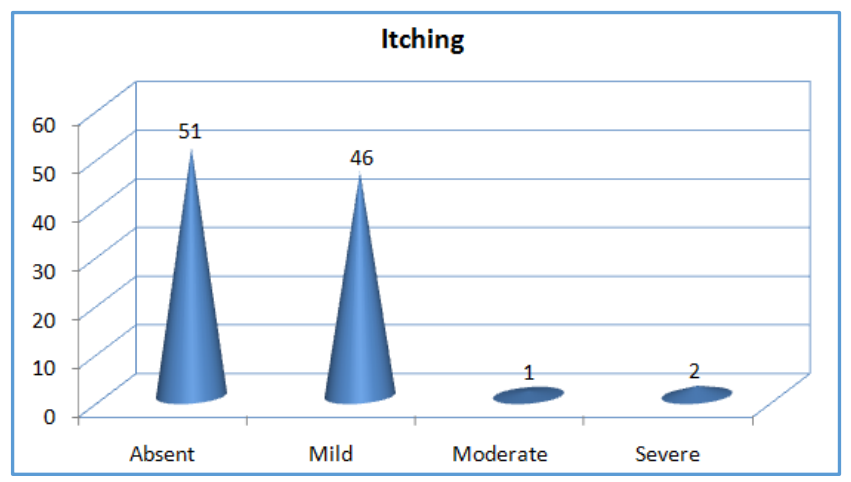

As reported in literature, most cases had a self-limiting course and the disease lasted for 6 weeks. ${ }^{7}$ In our study, 91\% of patients had a self-limiting course of about $6-9$ weeks. The longest duration of 14 weeks was observed in 2 patients, one had EMF-like PR, the other one had Classical Pityriasis rosea with palmoplantar involvement.

In most of the patients (97\%) the lesions vanished without trace, which was similar to that in literature. Postinflammatory hypopigmentation was seen in 3 patients (3\%). However, hyperpigmentation was not seen like that reported in literature.

Nail dystrophy had been reported by Silvers and Glickman 1974, following Pityriasis rosea. ${ }^{8}$ In our study, none of the patients showed any nail changes.

Literature reports that PR is associated with skin diseases like atopy, seborrhoeic dermatitis and acne vulgaris. ${ }^{9}$ In our study also association with seborrhoeic dermatitis and acne vulgaris have been found.

\begin{tabular}{|c|c|}
\hline Associated Skin Disease & No. of Patients \\
\hline Acne vulgaris & 06 \\
\hline Canites & 03 \\
\hline Seborrhoeic Dermatitis & 04 \\
\hline Nevus & 03 \\
\hline M.C & 01 \\
\hline L.N & 01 \\
\hline Accessory Nipple & 01 \\
\hline Eczema & 01 \\
\hline Fibrous polyp & 01 \\
\hline P. alba & 01 \\
\hline Pediculosis capitis & 01 \\
\hline Polymorphic light eruption & 01 \\
\hline Striae distensae & 02 \\
\hline Skin tag & 02 \\
\hline Lipoma & 01 \\
\hline Tinea versicolor & 02 \\
\hline Tinea cruris & 01 \\
\hline Traumatic fissure & 01 \\
\hline Androgenic alopecia & 01 \\
\hline \multicolumn{2}{|c|}{ Table 8. Associated skin diseases } \\
\hline
\end{tabular}

\section{Total Duration of the Disease}

\begin{tabular}{|c|c|}
\hline Total Duration & No. of Patients \\
\hline 6 weeks & 27 \\
\hline 7 weeks & 23 \\
\hline 8 weeks & 31 \\
\hline 9 weeks & 10 \\
\hline 10 - 14 weeks & 09 \\
\hline \multicolumn{2}{|c|}{ Table 9. Total duration of the disease } \\
\hline
\end{tabular}




\section{Jemds.com}

In $81 \%$ of patients, the lesions resolved within a period of 6 - 8 weeks.

There was history of recurrence in 2 cases in our study. These findings are also consistent with those in literature, where recurrence has been seen in $2 \%$ of the cases. ${ }^{10}$

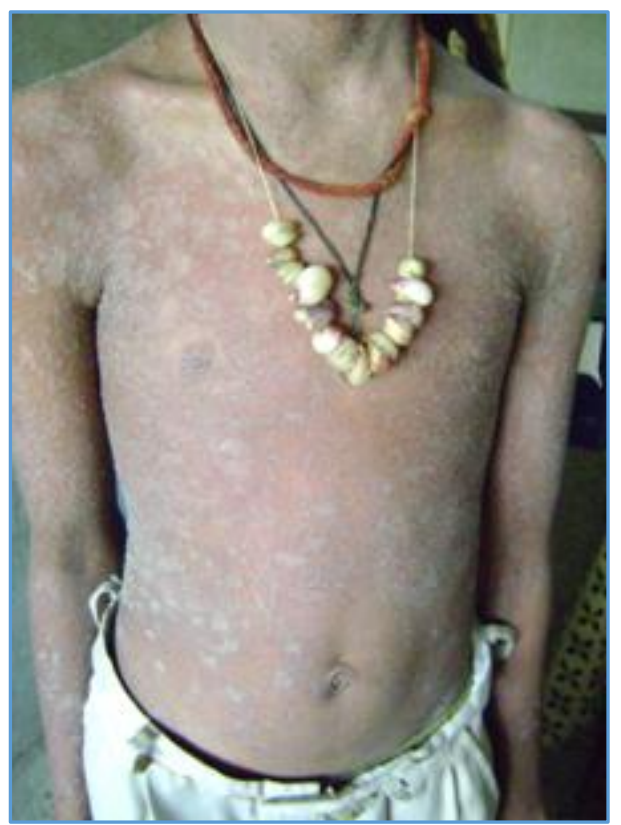

Figure 1. Lichenoid PR

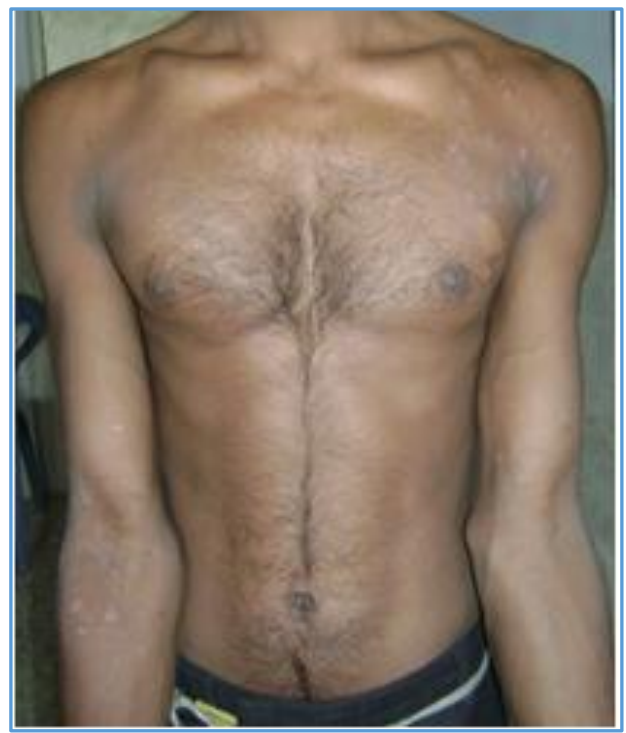

Figure 2. Flexural PR

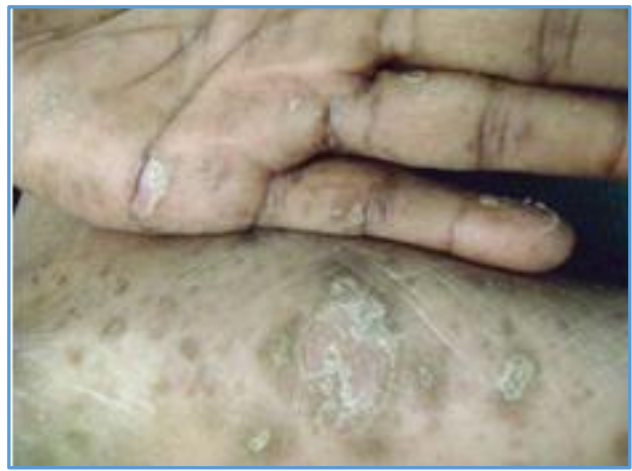

Figure 3. Palmoplantar Involvement
Original Research Article

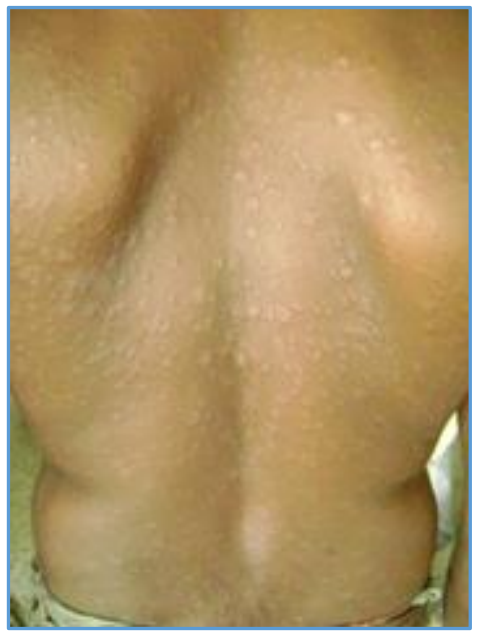

Figure 4. Typical Christmas Tree Appearance

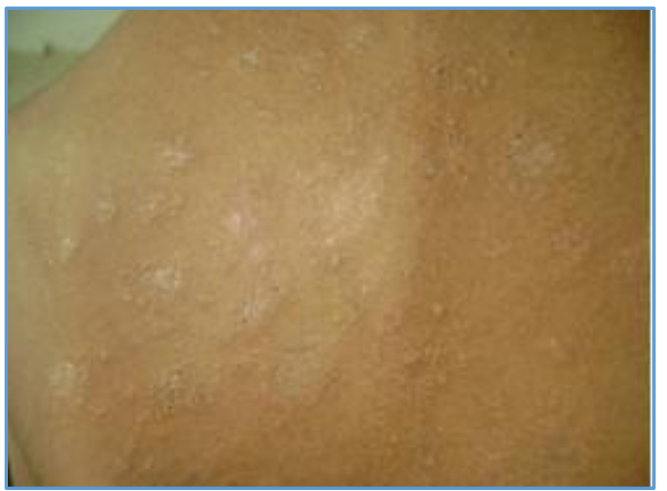

Figure 5. EMF-like PR

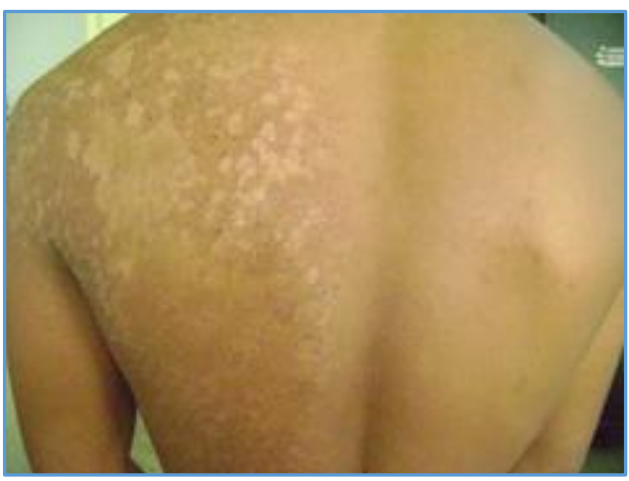

Figure 6. Unilateral PR

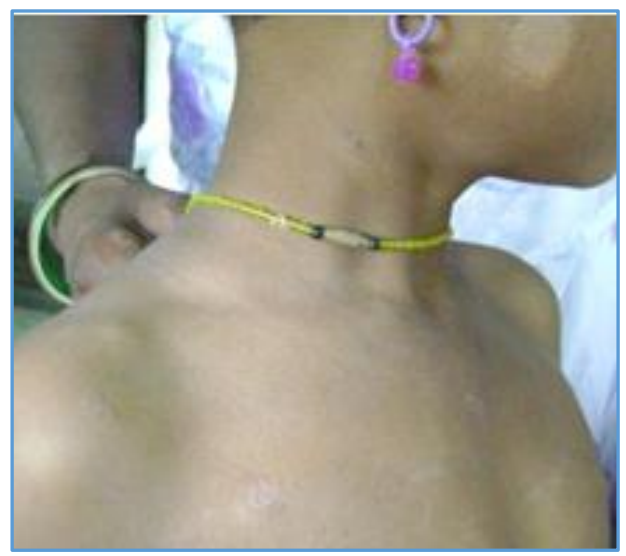

Figure 7. Inverse PR 


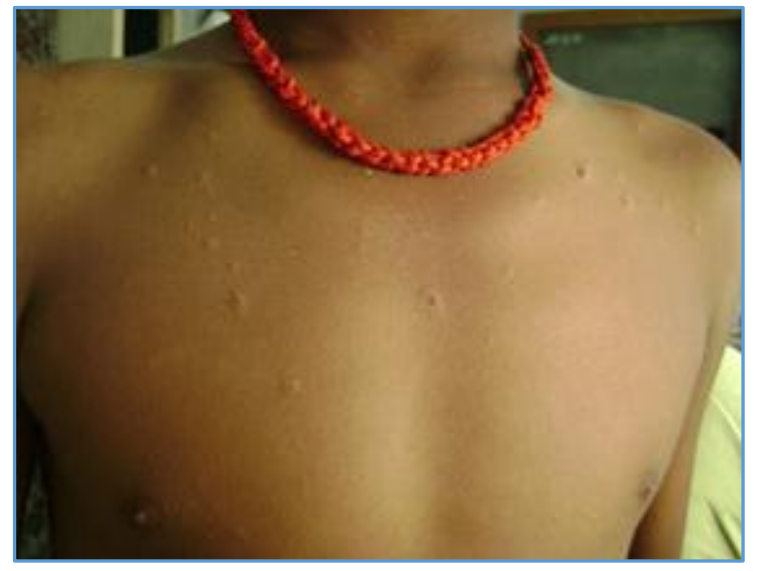

Figure 8. Papular PR

\section{DISCUSSION}

Pityriasis rosea (PR) of Gibert is defined as an acute, selflimiting disease, probably infective in origin, affecting mainly children and young adults and characterised by a distinctive skin eruption and minimal constitutional symptoms ${ }^{11}$ or a self-limiting disorder characterised by the development of asymptomatic erythematous scaly macules on the trunk. Pityriasis means fine scales; rosea denotes rose coloured or pink.

\section{Epidemiology}

The average annual incidence at one centre was reported to be 0.16 percent (158.9 cases per 100,000 person-years). Traore A et al in his cross-sectional study calculated the prevalence of PR to be $0.6 \% .{ }^{12} \mathrm{PR}$ affects all ages from infants to the elderly. It is uncommon in young children (less than 2 years) and elderly (more than 65 years). ${ }^{9}$ Most patients are between the years of 10 and 35.9,10 The youngest reported patient was three months old. The oldest reported patient was 83 years old. 10

Camille-Melchoir Gibert stated that females are affected more often than males. Many studies have reported a slight female preponderance, the most frequently reported male: female ratio being 1: 1.2 to $1: 1.5 .1,9$ The reason for the apparent female predominance is unknown.

In temperate zone, it is more common during winter. In tropical regions, PR has been found to be more common during hot and dry season. ${ }^{1}$

\section{Aetiology}

The evidence to support an infectious aetiology for PR is its distinct clinical course. There is a primary skin lesion followed by a secondary eruption with complete remission, mostly within about eight weeks. This course of the disease is similar to most of the viral infections. Moreover, many patients do not have a second attack due to lifelong immunity, a phenomenon which is commonly seen in many viral diseases.

Herpes virus like particles has been found in $71 \%$ of PR lesions. HHV6 and HHV7 have been suggested as the cause for the eruption. The viral DNA is reported to be present in peripheral blood mononuclear cells in the lesional and unaffected skin of majority (80\% - 100\%) of individuals with acute PR. HHV7 is detected slightly more frequently than HHV6, but often both viruses are found. However, evidence for the presence and activity of HHV-6 or HHV-7 is also found in a proportion $(10 \%-44 \%)$ of unaffected individuals. Hence, its role as a causative agent is yet to be proved.9,13

\section{Probable Pathogenesis}

HHV-7 and HHV-6 do not infect keratinocytes, but instead infect CD4+ T cells within blood and are retained within these cells in a latent form in most individuals. These cells are the likely source of cell-free viral DNA found in plasma or serum samples of patients with PR. They are also the likely source of the scattered perivascular and perifollicular virus-positive cells observed within some lesions of PR.

\section{Clinical Features and Diagnosis}

The herald patch is the first lesion to appear in a PR patient. It is a solitary round or oval lesion with a central wrinkled salmon coloured area and a darker red peripheral zone separated by a collarette of fine scaling. It may vary from 1-10 $\mathrm{cm}$ in diameter. The herald patch may occur anywhere on the body, although the trunk and upper arms are its predilected sites, i.e. in the areas covered by clothes. ${ }^{14}$ Rarely, it may be on the face, scalp or the penis. ${ }^{9}$ When the plaque is irritated, it may have an eczematous papulovesicular appearance. The herald patch is seen in $80 \%$ of all PR patients. ${ }^{2}$ In another study where a series of 127 patients were examined, $76 \%$ were reported to have a herald patch.

Prodromal symptoms are usually absent. ${ }^{9}$ In a minority of patients, flu-like symptoms have been reported including general malaise, headache, nausea, loss of appetite, fever and arthralgias.

The herald patch is followed by the secondary eruption, the interval being 5 to 15 days. ${ }^{9}$ Two main types of lesions are seen, one is the lesion of similar morphology as the herald patch but smaller in size and the other is small, red, nonscaling papules that gradually increase in number and spread peripherally. Both the forms can exist concomitantly. Old lesions usually fade in two weeks, but new lesions will continue to appear in crops at 2 - 3 days interval over a week or 10 days. ${ }^{14}$ Each lesion shows circinate scaling where the scales are attached only at the periphery, sometime resulting in the characteristic "Hanging Curtain" sign.

In classical cases only the trunk and proximal aspects of the extremities are involved, resulting in T-shirt-and-shorts, high-necked short sleeved vest or bathing suit pattern. Distribution may be distal to the elbow in $4.8 \%$ to $12 \%$ of cases and distal to the knees or the elbows in $6 \%$ to $15.3 \%$ of cases. ${ }^{9}$ The face is usually spared, except in children. ${ }^{9}$ Palms and soles are spared in most cases. Palmoplantar involvement in PR was reported by Klauder JV as early as $1924.5^{5}$ On the anterior and posterior aspect of trunk, the characteristic orientation of the secondary eruptions along the skin cleavage line has been described in various terms as Christmas tree pattern, inverted Christmas tree pattern and fir tree pattern.

Pruritus is severe in $25 \%$ of patients; slight-to-moderate in $50 \%$ and absent in $25 \%$ of patients. When PR is irritated, itching is usually prominent.

The duration of the rash varies from 2 to 12 weeks, but may last for as long as five months which is known as PR perstans. ${ }^{7}$ Post-inflammatory hyper- or hypopigmentation may also last for months, but usually the lesion vanishes without trace. 10 
Relapse may occur in $2 \%$ of cases after an interval of a few months or many years. In a series of 826 patients, the rate of relapse was noted as $2.8 \% .^{5}$

Up to $39 \%$ of patients with PR may have some atypical features. Atypical features include atypical rash morphology, rash size, rash distribution and site of the lesions. ${ }^{12}$ The Herald patch may be absent or undetected in about $20 \%$ of cases. 9 There may be two or more patches. The primary plaque may be the sole manifestation of the disease or only one of two lesion. Atypical rash morphology includes papular, vesicular, purpuric or haemorrhagic, urticarial, lichenoid and EMF-like forms. ${ }^{9}$

Pityriasis rosea gigantea of Darier is rare characterised by large sized plaques, which can have sizes up to the patient's own palm. Papular PR is the other extreme in the size of PR lesions. ${ }^{15}$ It is more often seen in children. The secondary eruption is numerous small papules $1-2 \mathrm{~mm}$ in diameter. 8

Fewer and larger lesions often localised to the axillae or inguinal region may be seen known as Pityriasis circinata et marginata. ${ }^{5}$ Acrally distributed secondary rash is known as PR inversus. ${ }^{16}$ Cases with strictly unilateral involvement have been reported. ${ }^{17}$

Asymptomatic intraoral lesions in the form of tiny punctate haemorrhages with pinhead erosion discrete and slightly elevated lesions sometimes with superficial erosions have been reported. Drugs including arsenic, ${ }^{11}$ tyrosine kinase inhibitors, captopril, ${ }^{18}$ gold, isotretinoin, lithium, nonsteroidal anti-inflammatory agents, omeprazole ${ }^{18}$ and terbinafine, ${ }^{19}$ have been implicated in causing PR-like rashes.

Lymphadenopathy may occur in patients with PR, especially early in the course of the disease and in association with flu-like symptom. Pitting of nails and onychodystrophy after PR has also been reported.20 Other associated skin diseases are atopy, seborrhoeic dermatitis and acne vulgaris. Involvements of internal organs have not been documented. No complications have been reported except for occasional mild flu-like symptom.

\section{Investigations}

PR is a clinical diagnosis. Lesional histopathological changes are non-specific. Taking a lesional biopsy thus cannot confirm a diagnosis of PR. Histopathological examination was not performed even in a recent clinical trial on PR, as it seldom helps in diagnosis according to the investigators. For adolescents at least, secondary syphilis should be excluded with serology tests for all cases diagnosed with PR, especially when the palms or soles are affected. Elevation of the erythrocyte sedimentary rate, a slight decrease in the number of T-lymphocytes and an increase in B-lymphocytes were reported. ${ }^{5}$

\section{Treatment}

Since PR is self-limited, there is no need for active treatment for all patients. Education and reassurance is enough for most of the patients. Water, Soap, Wool and Sweating may cause irritation and should be avoided in acute stages. New clothing must also be avoided. For patients with mild pruritus, zinc oxide or calamine lotion will suffice. For patients with pruritus severe enough to disturb the quality of life, a course of Erythromycin can be given in addition. Tab. Erythromycin $250 \mathrm{mg}$ QID for 2 weeks; for children $25-40 \mathrm{mg} / \mathrm{kg} /$ day in four divided doses for 2 weeks) ${ }^{21}$ along with antihistamines and mid potency topical corticosteroid for symptomatic relief of pruritus. Systemic corticosteroids should be restricted to adult patients with exceptionally recalcitrant and symptomatic PR resistant to other treatments. ${ }^{22}$ For patients with flu-like symptoms and/or extensive skin diseases, oral Acyclovir $800 \mathrm{mg}, 5$ times daily for 1 week may hasten recovery from disease. ${ }^{23}$ Phototherapy, ultraviolet radiation in erythmogenic doses has been found to be useful. But postinflammatory, pigmentation at the site of the PR lesion may be a complication. ${ }^{24}$ Dapsone has been used in severe vesicular PR. ${ }^{25}$

\section{CONCLUSION}

Pityriasis rosea is a self-limiting skin disease. Clinical diagnosis of Pityriasis rosea at the earliest presentation is important to avoid unnecessary investigations and to give reassurance about the self-limiting nature of the disease. The practicing dermatologist should be aware of the various clinical presentations of the disease. There is no need for active treatment in most of the patients. The present study has revealed male preponderance. The age of incidence was found to be high in adolescents and young adults. No familial incidence was observed. Factors like wearing of new garments, stress and upper respiratory tract infections were found to precipitate the disease in some cases. In most of the patients, the lesions vanished without trace.

\section{REFERENCES}

[1] Chuang TY, Ilstrup DM, Perry HO, et al. Pityriasis rosea in Rochester, Minnesota, 1969-78. J Am Acad Dermatol 1982;7(1):80-9.

[2] Björnberg A, Hellgren L. Pityriasis rosea. A statistical, clinical, and laboratory investigation of 826 patients and matched healthy controls. Acta derm venereol suppl (stockh) 1962;42(Suppl 50):1-68.

[3] Abercrombie GF. Pityriasis rosea. Proc R Soc Med 1962;55:556-7.

[4] Pringle JJ. Case presentation, section on dermatology, royal society of medicine. Br J Dermatol 1915;27:309.

[5] Klauder JV. Pityriasis rosea with particular reference to its unusual manifestations. JAMA 1924;82(3):17883.

[6] Cavanaugh RM. Pityriasis rosea in children. A review. Clin pediatr (phila) 1983;22(3):200-3.

[7] Gonzalez LM, Allen R, Janniger CK, et al. Pityriasis rosea: an important papulosquamous disorder. Int J Dermatol 2005;44(9):757-64.

[8] Hurly HJ. Papulosquamous eruption and exfoliative dermatitis. Dermatogy 1975;1:427-31.

[9] Champion RH, Burton JL, Burns DA, et al. Viral rashes. In: Rook's textbook of dermatology. $6^{\text {th }}$ edn. Oxford: Blackwell Sciences 1998:1092-5.

[10] Truhan AP. Pityriasis rosea. Am Fam Physician 1984;29(5):193-6.

[11] Jackson R. The lines of blaschko: a review and reconsideration: observations of the cause of certain unusual linear conditions of the skin. Br J Dermatol 1976;95(4):349-60.

[12] Traore A, Korsaga-Some N, Niamba P, et al. Pityriasis rosea in secondary schools in Ouagadougou, Burkina Faso. Ann Dermatol Venereol 2001;128(5):605-9. 
[13] Kempf W, Adams V, Kleinhans M, et al. Pityriasis rosea is not associated with human herpesvirus 7. Arch Dermatol 1999;135(9):1070-2.

[14] Parsons JM. Pityriasis rosea update: 1986. J Am Acad Dermatol 1986;15(2 Pt 1):159-67.

[15] Gibney MD, Leonardi CL. Acute papulosquamous eruption of the extremities demonstrating an isomorphic response. Inverse pityriasis rosea (PR). Arch Dermatol 1997;133(5):651-4.

[16] Chuh A, Zawar V, Lee A. Atypical presentations of pityriasis rosea: case presentations. J Eur Acad Dermatol Venereol 2005;19(1):120-6.

[17] Wilkin JK, Kirkendall WM. Pityriasis rosea-like rash from captopril. Arch Dermatol 1982;118(3):186-7.

[18] Buckley C. Pityriasis rosea-like eruption in a patient receiving omeprazole. $\mathrm{Br} \mathrm{J}$ Dermatol 1996;135(4):660-1.

[19] Gupta AK, Lynde CW, Lauzon GJ, et al. Cutaneous adverse effects associated with terbinafine therapy: 10 case reports and a review of the literature. $\mathrm{Br} \mathrm{J}$ Dermatol 1998;138(3):529-32.
[20] Silvers S. Pityriasis rosea followed by nail dystrophy. Arch Dermatol 1964;90:31.

[21] Sharma PK, Yadav TP, Gautam RK, et al. Erythromycin in pityriasis rosea: a double-blind, placebo-controlled clinical trial. J Am Acad Dermato 2000;42(2 Pt 1):2414.

[22] Tay YK, Goh CL. One-year review of pityriasis rosea at the national skin centre, Singapore. Ann Acad Med Singapore 1999;28(6):829-31.

[23] Drago F, Vecchio F, Rebora A. Use of high-dose acyclovir in pityriasis rosea. J Am Acad Dermatol 2006;54(1):82-5.

[24] Arndt KA, Paul BS, Stern RS, et al. Treatment of pityriasis rosea with UV radiation. Arch Dermatol 1983;119(5):381-2.

[25] Anderson CR. Dapsone treatment in a case of vesicular pityriasis rosea. Lancet 1971;298(7722):493. 